\title{
Plasma heat shock protein 90alpha as a biomarker for the diagnosis of liver cancer: in patients with different clinicopathologic characteristics
}

\author{
Yueting Han ${ }^{1}$, Youqin Zhang ${ }^{2}$, Lin Cui ${ }^{1}$, Ze Li ${ }^{1}$, Honglei Feng ${ }^{1}$, Ying Zhang ${ }^{1}$, Da Sun ${ }^{3}$ and Li Ren ${ }^{\text {* }}$
}

\begin{abstract}
Purposes: The purposes of this study were to assess the correlation between the plasma level of Hsp90a and the clinicopathological characteristics of patients with liver cancer and compare the diagnostic efficacy of Hsp90a, AFP, CEA, and CA199 in HCC.

Experimental design: A total of 200 individuals, including 140 patients with liver cancer or benign liver diseases and 60 healthy people, were enrolled for quantitative measurement of plasma Hsp90a by ELISA.

Results: The plasma level of Hsp90a was significantly different between patients with liver cancer or benign liver diseases and healthy controls ( $P<0.001)$. The sensitivity, specificity, and AUC (95\% Cl) of Hsp90a were 93.2\%, 85.4\%, and $0.931 \%$ (0.891-0.972\%), respectively, when Hsp90a was applied to differentiate liver cancer patients and healthy controls. Significant positive correlations between the plasma Hsp90a level and clinicopathological characteristics such as the history of basic liver disease $(P=0.038)$, active stage of hepatitis $(P=0.039)$, Child-Pugh score $(P<0.001)$, size of focal liver lesions $(P=0.004)$, and extrahepatic metastasis $(P<0.001)$ were observed. AFP + Hsp90a was the best combination strategy for the auxiliary diagnosis of HCC, with a sensitivity of $95.7 \%$, a specificity of $97.5 \%$, and an AUC of 0.990 (0.976-1.000). The level of plasma Hsp90a decreased significantly $(P<0.001)$ after resection of tumor tissue.

Conclusions: This study demonstrated that plasma Hsp90a levels are useful as a diagnostic biomarker in liver cancer and may predict the responses of patients with liver cancer to surgery. Some clinicopathological characteristics could affect the plasma Hsp90a levels.
\end{abstract}

Keywords: Heat shock protein 90a, Liver cancer, Pathology, Biomarker

\section{Introduction}

Primary liver cancer (PLC) ranks fourth among common malignant tumors. It is the second leading cause of cancer deaths in China. The crude incidence and mortality rates are $26.92 / 10^{5}$ and $23.72 / 10^{5}$ [1], respectively. Early

\footnotetext{
* Correspondence: RenLi722722@163.com

'Department of Clinical Laboratory, Tianjin Medical University Cancer Institute and Hospital, National Clinical Research Center for Cancer, Tianjin's

Clinical Research Center for Cancer, Key Laboratory of Cancer Prevention and Therapy, Tianjin 300060, China

Full list of author information is available at the end of the article
}

diagnosis is crucial to the treatment because of the poor prognosis of advanced liver cancer [2, 3]. Good tumor markers play a key role in high-risk screening, early diagnosis, and guiding treatment. Alpha-fetoprotein (AFP) is the most commonly used tumor marker in the screening and clinical diagnosis of patients with liver cancer. The sensitivity and specificity of AFP to hepatocellular carcinoma (HCC) in all stages are $41-65 \%$ and 80-94\%, respectively [4]. The sensitivity of AFP to HCC in phase A of Barcelona clinical liver cancer is less than

C C The Author(s). 2021 Open Access This article is licensed under a Creative Commons Attribution 4.0 International License, which permits use, sharing, adaptation, distribution and reproduction in any medium or format, as long as you give appropriate credit to the original author(s) and the source, provide a link to the Creative Commons licence, and indicate if changes were made. The images or other third party material in this article are included in the article's Creative Commons licence, unless indicated otherwise in a credit line to the material. If material is not included in the article's Creative Commons licence and your intended use is not permitted by statutory regulation or exceeds the permitted use, you will need to obtain permission directly from the copyright holder. To view a copy of this licence, visit http://creativecommons.org/licenses/by/4.0/ The Creative Commons Public Domain Dedication waiver (http://creativecommons.org/publicdomain/zero/1.0/) applies to the data made available in this article, unless otherwise stated in a credit line to the data. 
50\% [5]. Meanwhile, AFP is less sensitive to intrahepatic cholangiocarcinoma (ICC), which further highlights its incapability in diagnosing different types of liver cancer [6]. Therefore, a new index was needed to complement AFP in clinical practice so as to improve the early diagnostic rate, therapeutic effect, and prognosis of liver cancer.

Heat shock protein 90 $\alpha$ (Hsp90 $\alpha$ ), a conserved and essential molecular chaperone, is important in enabling replicative immortality, inducing angiogenesis, and activating invasion/metastasis of malignant cells. Some studies showed that Hsp90 $\alpha$ could be actively translocated into the extracellular space by malignant tumor cells [7]. In addition, the level of Hsp90 $\alpha$ in the plasma of patients with malignant tumors increased significantly and correlated positively with the degree of malignancy and the ability of metastasis [8]. A large-scale, multicenter clinical trial data showed that plasma Hsp90 $\alpha$ could be used as an early diagnostic marker in the diagnosis of patients with liver cancer, and its diagnostic performance was better than that of AFP (sensitivity $92.7 \%$ and specificity 91.3\%). In patients undergoing liver surgery or interventional treatment, the dynamic change in the Hsp90 $\alpha$ level could help monitor the therapeutic effect [9].

Few studies reported the role of Hsp90 $\alpha$ in the patients of liver cancer with different clinicopathologic characteristics, the differentiation of benign and malignant liver diseases, and the monitoring of the curative effect of liver cancer $[9,10]$. Although the benefits of HSP90 $\alpha$ as a diagnostic factor have been described elsewhere already, we still want to evaluate this biomarker in patients of our center. It is necessary to provide more real-world data, considering the preclinical profile of HSP90 $\alpha$-related solutions, based on the current situation that it lacks previous studies and available cohorts are relatively small. This study enrolled patients with liver cancer admitted to the Tianjin Medical University Cancer Institute and Hospital to explore the role of Hsp90 $\alpha$ in liver cancer diagnosis and treatment, providing a scientific basis for its application in this field.

\section{Methods}

\section{Participants}

One-hundred forty treatment-naïve patients who were hospitalized in the Tianjin Medical University Cancer Institute and Hospital from September 2018 to February 2019 for liver diseases, were enrolled in this study. To be specific, 118 patients with liver cancer and 22 patients with liver abscess and hemangioma were, respectively, grouped into liver cancer (postoperative followed-up the patients undergoing hepatic carcinectomy for 8 weeks) and liver benign tumor groups. The staging of these liver cancers was performed according to American Joint Committee on Cancer Classification (AJCC, 8th edition)
[11]. In addition, 60 healthy people were included in the control group after the health examination.

The study was approved by the institutional ethics review committee of Tianjin Medical University Cancer Institute and Hospital. Signed informed consent forms were obtained from all participants based on each committee's regulations.

\section{Testing of blood samples}

Peripheral blood samples (EDTA-K2 anticoagulant) from all participants were collected before anticancer therapy and centrifuged at $3000 \mathrm{rpm}$ for $10 \mathrm{~min}$ in $4 \mathrm{~h}$. The plasma was stored at $-20{ }^{\circ} \mathrm{C}$ until further use. The plasma Hsp90 $\alpha$ concentration was quantitatively measured using a commercially available enzyme-linked immunosorbent assay (ELISA) kit (Batch No. 190126, Protgen Co., Ltd., Yantai, Shandong Province, China) according to the manufacturer's recommendations. Briefly, diluted plasma samples and standard samples were added to a 96-well microplate precoated with monoclonal antibody to Hsp90 $\alpha$. An HRP-conjugated antiHsp $90 \alpha$ antibody $(50 \mu \mathrm{L})$ was added to the plate, and then the plate was incubated at $37^{\circ} \mathrm{C}$ for $1 \mathrm{~h}$. The reaction was visualized by adding $50 \mu \mathrm{L}$ chromogen TMB (solution A) and $50 \mu \mathrm{L}$ chromogen TMB (solution B) sequentially to each well and incubated for $20 \mathrm{~min}$ at 37 ${ }^{\circ} \mathrm{C}$. Finally, the reaction was stopped by adding $50 \mu \mathrm{L}$ Stop Solution to each well. The optical density was measured at $450 \mathrm{~nm}$ and referenced to $570 \mathrm{~nm}$ on a spectrophotometer. The standard curve was generated by plotting the logarithm of average optical density obtained for each of the six standard samples on the vertical $(Y)$ axis versus the logarithm of corresponding concentrations on the horizontal $(X)$ axis. The absorbance of samples was then calculated with the method of substitution in the standard curve to determine the level of Hsp90 $\alpha$ in the plasma sample. Double logarithmic curve fitting was recommended, and the coefficient of correlation $\left(R^{2}\right)$ was required to be more than 0.980 .

The serum levels of carcinoembryonic antigen (CEA), AFP, and CYFRA21-1 were also measured using a commercially available chemoluminescence (CL) kit (R\&D Systems).

\section{Follow-up}

For the patients with liver cancer who continued to receive postoperative follow-up, plasma samples were still collected in the 4th week after surgery to do other laboratory examination (including blood routine test, assessment of liver and kidney function, five items for hepatitis B, hepatitis B virus (HBV) DNA, AFP, and Hsp90 $\alpha$ ). Besides, the imaging examination (chest, abdomen, pelvic enhancement CT, and/or MRI) was performed at the 8th week, then those results were 
Table 1 Clinicopathologic characteristics of patients with liver cancer

\begin{tabular}{|c|c|c|}
\hline Characteristics & & $\begin{array}{l}\text { Number } \\
\text { (percentage) }\end{array}$ \\
\hline \multirow[t]{2}{*}{$\operatorname{Sex}(n=118)$} & Male & $87(74)$ \\
\hline & Female & $31(26)$ \\
\hline \multirow[t]{2}{*}{ Age $(n=118)$} & $<60$ & $66(56)$ \\
\hline & $\geq 60$ & $52(44)$ \\
\hline \multirow[t]{2}{*}{ Source $(n=118)$} & Primary & $91(77)$ \\
\hline & Secondary & $27(23)$ \\
\hline \multirow[t]{3}{*}{ PLC histologic types $(n=91)$} & $\mathrm{HCC}$ & $67(74)$ \\
\hline & ICC & $20(22)$ \\
\hline & Other types & $4(4)$ \\
\hline \multirow[t]{4}{*}{ TNM stage $(n=118)$} & I & $20(17)$ \\
\hline & $\|$ & $12(10)$ \\
\hline & III & $27(23)$ \\
\hline & IV & $59(50)$ \\
\hline \multirow{4}{*}{$\begin{array}{l}\text { Primary organs of secondary liver } \\
\text { cancer }(n=27)\end{array}$} & Colorectal & $10(37)$ \\
\hline & Stomach & $3(11)$ \\
\hline & Pancreas & $4(15)$ \\
\hline & Other & $10(37)$ \\
\hline \multirow{3}{*}{$\begin{array}{l}\text { History of basic liver disease }(n= \\
\text { 118) }\end{array}$} & Viral hepatitis & $59(50)$ \\
\hline & Liver cirrhosis & $39(33)$ \\
\hline & $\begin{array}{l}\text { No basic liver } \\
\text { disease }\end{array}$ & $20(17)$ \\
\hline \multirow[t]{2}{*}{ Child-Pugh $(n=118)$} & $A / B$ & $59(50)$ \\
\hline & C & $59(50)$ \\
\hline \multirow[t]{2}{*}{ Morbidity ( $n=118)$} & Not recurrence & $85(72)$ \\
\hline & Recurrence & $33(28)$ \\
\hline
\end{tabular}

Table 2 Plasma Hsp90a levels in different groups

\begin{tabular}{|c|c|c|c|c|}
\hline \multirow{2}{*}{$\begin{array}{l}\text { Group } \\
\text { Liver cancer }\end{array}$} & \multicolumn{2}{|c|}{ Subgroup } & \multirow{2}{*}{$\begin{array}{l}\text { Number } \\
118\end{array}$} & \multirow{2}{*}{$\frac{\text { Plasma Hsp90a level }(\mathbf{n g} / \mathbf{m L})}{200.58 \pm 143.64}$} \\
\hline & - & & & \\
\hline & PLC & & 91 & $190.38 \pm 125.72$ \\
\hline & \multirow[t]{3}{*}{ Types } & $\mathrm{HCC}$ & 67 & $201.48 \pm 152.22$ \\
\hline & & ICC & 20 & $172.21 \pm 89.66$ \\
\hline & & Other types & 4 & $280.83 \pm 49.65$ \\
\hline & \multirow[t]{4}{*}{ Stage } & । & 20 & $103.42 \pm 37.80$ \\
\hline & & $\|$ & 12 & $151.59 \pm 44.16$ \\
\hline & & III & 27 & $174.85 \pm 97.65$ \\
\hline & & IV & 59 & $255.26 \pm 171.48$ \\
\hline Liver benign disease & \multicolumn{2}{|l|}{-} & 22 & $110.64 \pm 90.06$ \\
\hline Healthy control & \multicolumn{2}{|l|}{ - } & 60 & $35.07 \pm 15.42$ \\
\hline
\end{tabular}

evaluated and described by "complete response" (CR), "partial response" (PR), "stable disease" (SD), and "progressive disease" (PD) according to "Response Evaluation Criteria in Solid Tumors (RECIST) v1.1" [12].

Statistical analysis was performed using SPSS v21.0 software. The counting data were expressed as a percentage, and the $\chi^{2}$ test was used for comparison. The measurement data was described as mean \pm standard deviation. The one-way analysis of variance test was used for comparing independent samples with a normal distribution, and the rank-sum test was used for comparing independent samples with a nonnormal distribution. A $P$ value less than 0.05 was considered statistically significant. Receiver operating characteristic (ROC) curves were constructed to assess the sensitivity, specificity, and respective areas under the curves (AUCs) with a 95\% confidence interval $(\mathrm{CI})$. The optimum cutoff value was determined for the diagnosis by maximizing the sum of sensitivity and specificity, minimizing the square root of the sum $\left[(1-\text { Sensitivity })^{2}+(1-\text { Specificity })^{2}\right]$, and minimizing the distance between the point and the top-left corner of the ROC curve (where sensitivity $=1$ and specificity $=1$ ). The correlation between the clinicopathological characteristics and the plasma Hsp90 $\alpha$ level in the liver cancer group was analyzed using the Spearman rank correlation analysis. The diagnostic efficacy of the combined detection of multiple tumor markers was analyzed using the binary logistic regression analysis

\section{Results}

Clinical data

This study enrolled 118 patients (average age of $50.69 \pm$ 9.47 years) with liver cancer. At baseline, most of them had history of basic liver disease and were in the advanced stage. Forty-four patients with liver cancer underwent hepatic carcinectomy. Thirty three patients

\section{Statistical analysis}


Table $3 P$ value of the plasma Hsp90a level in different stages of liver cancer

\begin{tabular}{ll}
\hline Group & $P$ value \\
\hline I vs II & 0.005 \\
II vs III & 0.831 \\
III vs IV & 0.046 \\
I + II vs II + IV & $<0.001$ \\
Non-liver cancer vs I + I & $<0.001$ \\
I vs III & 0.034 \\
I vs IV & 0.002 \\
|| vs IV & 0.042
\end{tabular}

Bold $P$ values are significant. had a recurrence during the follow-up. The clinicopathologic characteristics from patients with liver and lung cancer were obtained and are summarized in Table 1.

\section{Auxiliary diagnostic effect of plasma Hsp90a level on liver cancer}

The results showed that the level of Hsp90 $\alpha$ in the plasma of the liver cancer group, benign tumor group, and healthy control group was significantly different $(P$ $<0.001)$. The plasma level of Hsp90 $\alpha$ was significantly higher in patients with liver cancer $(200.58 \pm 143.64 \mathrm{ng} /$ $\mathrm{mL})$ than in patients with benign tumors (110.64 \pm 90.06 $\mathrm{ng} / \mathrm{mL}$ ) and healthy controls (35.07 $\pm 15.42 \mathrm{ng} / \mathrm{mL})$. Among these, the plasma level was significantly higher in patients with stage I and stage II liver cancer (resectable) than in those with non-liver cancers $(P<0.001)$. The plasma level of Hsp90 $\alpha$ was not statistically significant $(P=0.831)$ in different histological types of primary liver cancer. The plasma level of Hsp90 $\alpha$ in patients with

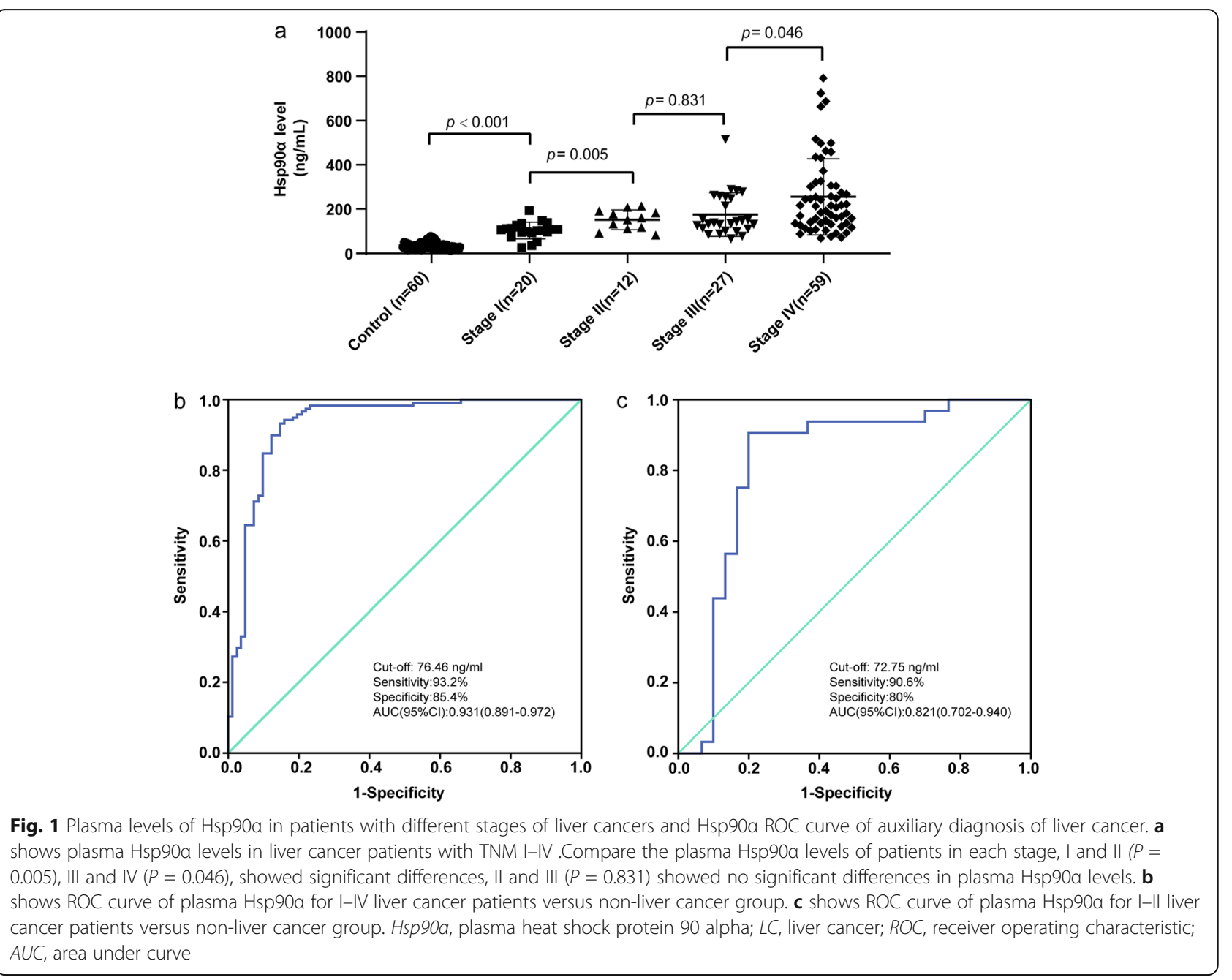


Table 4 Plasma levels of Hsp90a in patients with liver cancer with different clinicopathological characteristics

\begin{tabular}{|c|c|c|c|c|}
\hline Characteristic & & Number & $\begin{array}{l}\text { Plasma Hsp90a level } \\
(\mathrm{ng} / \mathrm{mL})\end{array}$ & $P$ value \\
\hline \multirow[t]{2}{*}{ Sex } & Male & 87 & $207.79 \pm 144.91$ & 0.153 \\
\hline & Female & 31 & $180.35 \pm 140.34$ & \\
\hline \multirow[t]{2}{*}{ Age } & $<60$ & 66 & $221.23 \pm 160.92$ & 0.184 \\
\hline & $\geq 60$ & 52 & $174.38 \pm 114.34$ & \\
\hline \multirow[t]{2}{*}{ History of hepatitis } & Yes & 59 & $245.14 \pm 181.37$ & 0.024 \\
\hline & No & 59 & $156.02 \pm 68.42$ & \\
\hline \multirow[t]{2}{*}{ History of cirrhosis } & Yes & 39 & $269.71 \pm 206.83$ & 0.040 \\
\hline & No & 79 & $166.45 \pm 80.85$ & \\
\hline \multirow[t]{2}{*}{ Active stage of liver disease } & Yes $^{*}$ & 17 & $221.05 \pm 148.62$ & 0.040 \\
\hline & No & 17 & $134.07 \pm 26.79$ & \\
\hline \multirow[t]{2}{*}{ Child-Pugh } & $A / B$ & 59 & $155.21 \pm 100.03$ & 0.025 \\
\hline & C & 59 & $255.26 \pm 171.48$ & \\
\hline \multirow[t]{2}{*}{ Morbidity } & 1st Occurrence & 118 & $217.75 \pm 104.27$ & 0.042 \\
\hline & Recurrence & 33 & $136.12 \pm 49.23$ & \\
\hline \multirow[t]{2}{*}{ Source } & Primary & 91 & $190.38 \pm 125.72$ & 0.038 \\
\hline & Secondary & 27 & $249.78 \pm 154.61$ & \\
\hline \multirow[t]{4}{*}{ Primary organs of secondary liver cancer } & Colorectal & 10 & $221.90 \pm 192.85$ & 0.896 \\
\hline & Stomach & 3 & $133.89 \pm 41.05$ & \\
\hline & Pancreas & 4 & $205.56 \pm 137.48$ & \\
\hline & Other & 10 & $220.12 \pm 186.96$ & \\
\hline \multirow[t]{2}{*}{ Size of focal liver lesions } & $<3 \mathrm{~cm}$ & 10 & $123.31 \pm 26.01$ & 0.006 \\
\hline & $3 \mathrm{~cm}$ & 22 & $177.71 \pm 54.33$ & \\
\hline \multirow[t]{3}{*}{ Extrahepatic metastasis } & Yes & 33 & $277.20 \pm 183.01$ & $<0.001$ \\
\hline & No & 22 & $115.11 \pm 61.26$ & \\
\hline & N/A & 63 & $212.24 \pm 133.91$ & \\
\hline
\end{tabular}

* HBV DNA $>10^{4}$. Bold $P$ values are significant.

different stages of liver cancers was statistically significant $(P=0.005,0.046$, and $<0.001$ for I vs II, III vs IV, and I + II vs III + IV, respectively). According to the ROC curve, the sensitivity, specificity, and AUC (95\% CI) were $93.2 \%, 85.4 \%$, and $0.931 \%(0.891-0.972 \%)$, respectively (see Tables 2 and 3 and Fig. 1).

Plasma levels of Hsp90a in patients with liver cancer with different clinicopathological characteristics

The results showed that the history of basic liver disease; active stage of hepatitis; primary, recurrent, and secondary cancers; extrahepatic metastasis; size of focal liver lesions; and classification of liver function had a significant influence on the plasma level of Hsp90 $\alpha$. Meanwhile, no difference in the plasma level of Hsp90 $\alpha$ was found between patients of different ages, sexes, histological sources, and primary organs of secondary liver cancers (see Table 4).
Table 5 Correlation between the plasma level of Hsp90a and the clinicopathological characteristics of patients with liver cancer

\begin{tabular}{lll}
\hline $\begin{array}{l}\text { Clinicopathological } \\
\text { characteristics }\end{array}$ & $\begin{array}{l}\text { Spearman coefficient } \\
(\boldsymbol{\rho})\end{array}$ & $\boldsymbol{P}$ value \\
\hline History of hepatitis & 0.209 & $\mathbf{0 . 0 3 8}$ \\
History of cirrhosis & 0.190 & $\mathbf{0 . 0 1 9}$ \\
Active stage of liver disease & 0.357 & $\mathbf{0 . 0 3 9}$ \\
Child-Pugh score & 0.224 & $<\mathbf{0 . 0 0 1}$ \\
First occurrence/recurrence & 0.044 & 0.185 \\
Primary/secondary & 0.055 & 0.266 \\
Size of focal liver lesions & 0.493 & $\mathbf{0 . 0 0 4}$ \\
Extrahepatic metastasis & 0.565 & $<\mathbf{0 . 0 0 1}$
\end{tabular}

Bold $P$ values are significant. 
Correlation between the plasma level of Hsp90a and the clinicopathological characteristics of patients with liver cancer

The results showed a significantly positive correlation between the plasma Hsp90 $\alpha$ level and clinicopathological characteristics such as the history of basic liver disease, active stage of hepatitis, Child-Pugh score, size of focal liver lesions, and extrahepatic metastasis. That is to say, a history of basic liver disease, active stage of basic liver disease, decompensation of liver function, size of focal liver lesions $>3 \mathrm{~cm}$, and extrahepatic metastasis could increase the plasma Hsp90 $\alpha$ level (see Table 5).

\section{Diagnosis of HCC by Hsp90a combined with AFP,} carcinoembryonic antigen (CEA), and carbohydrate antigen199 (CA199)

Among the 67 patients with HCC, 47 patients had AFP, CA199, and CEA baseline data, whereas among the 60 individuals in the control group, 40 patients had AFP, CA199, and CEA test data. The data analysis showed that for the four tumor markers, including $\mathrm{Hsp} 90 \alpha$, Hsp90 $\alpha$ had the highest sensitivity (95.7\%), and AFP had the highest specificity $(92.5 \%)$. The ROC curve of single and combined use of the four indicators showed that AFP + Hsp90 $\alpha$ was the best combination strategy for the auxiliary diagnosis of $\mathrm{HCC}$, with a sensitivity of $95.7 \%$, a specificity of $97.5 \%$, and an AUC of 0.990 (95\% CI, 0.976-1.000) (see Table 6 and Fig. 2).

\section{Dynamic changes of plasma levels of Hsp90a pre- and post-hepatic carcinectomy}

Dynamic changes reflecting the patients' condition could provide the clinical guidance for doctors. We therefore tentatively explored the efficacy monitoring capability of plasma Hsp90 $\alpha$ in patients undergoing hepatic carcinectomy. The results showed that the level of plasma Hsp90 $\alpha$ decreased significantly $(P<0.001)$ after resection of tumor tissue in 44 patients from $249.29 \pm 142.82$ to $131.01 \pm 63.23 \mathrm{ng} / \mathrm{mL}$ (see Table 7).

\section{Discussion}

Hsp90 $\alpha$ is a molecular chaperone involved in a variety of physiological and pathological signaling pathways. It is overexpressed in a variety of tumors, such as liver cancer, colorectal cancer, gastric cancer, lung cancer, breast cancer $[8,13-17]$, and so on. Similar to the result of a former large-scale, multicenter clinical trial, we found that plasma Hsp90 $\alpha$ exhibited a significantly higher diagnostic performance for liver cancer than AFP [9]. The results of the present study also confirmed that Hsp90 $\alpha$ could assist AFP in liver cancer diagnosis by improving the sensitivity and specificity of HCC. Compared with single detection, the combination of the two could further improve the sensitivity to $95.7 \%$ and specificity to 97.5\%. Therefore, the diagnosis using a combination of Hsp90 $\alpha$ and AFP is more economical and appropriate in clinical practice.

Transcriptome-proteome integrated assay showed that Hsp90 $\alpha$ is overexpressed in the HCC cells, serum, and tissues, and related to $\mathrm{CC}$ metastatic behavior and cancer-related signaling pathways [18]. The plasma level of Hsp90 $\alpha$ in our patients with liver cancer showed a significant upward trend with the progression in the clinical stage, and a significant positive correlation was observed. In particular, the level of Hsp90 $\alpha$ was significantly lower in patients with stage I and stage II liver

Table 6 Diagnostic efficacy of four tumor markers in HCC

\begin{tabular}{|c|c|c|c|c|c|}
\hline Index(es) & AUC $(95 \% \mathrm{Cl})$ & Sensitivity (\%) & Specificity (\%) & PPV (\%) & NPV (\%) \\
\hline AFP & $0.866(0.783-0.950)$ & 78.7 & 92.5 & 78.7 & 92.5 \\
\hline Hsp90a & $0.934(0.882-0.986)$ & 95.7 & 75.0 & 95.7 & 75.0 \\
\hline CEA & $0.694(0.584-0.804)$ & 51.1 & 81.5 & 27.7 & 100 \\
\hline CA199 & $0.700(0.592-0.808)$ & 48.9 & 81.5 & 48.9 & 85.0 \\
\hline $\mathrm{AFP}+\mathrm{Hsp} 90 \mathrm{a}$ & $0.990(0.976-1.000)$ & 95.7 & 97.5 & 74.5 & 70.0 \\
\hline AFP + CA199 & $0.896(0.829-0.964)$ & 74.5 & 100 & 40.4 & 72.5 \\
\hline $\mathrm{AFP}+\mathrm{CEA}$ & $0.903(0.933-0.972)$ & 78.7 & 97.5 & 23.4 & 75.0 \\
\hline CEA + Hsp90a & $0.932(0.879-0.984)$ & 70.2 & 100 & 27.7 & 60.0 \\
\hline CA199 + Hsp90a & $0.936(0.885-0.987)$ & 91.5 & 81.5 & 48.9 & 62.5 \\
\hline CEA + CA199 & $0.736(0.633-0.839)$ & 42.6 & 95.0 & 25.5 & 70.0 \\
\hline$A F P+C E A+C A 199$ & $0.900(0.833-0.967)$ & 76.6 & 100 & 21.3 & 62.5 \\
\hline $\mathrm{AFP}+\mathrm{CEA}+\mathrm{Hsp} 90 \mathrm{a}$ & $0.990(0.976-1.000)$ & 95.7 & 97.5 & 23.4 & 57.5 \\
\hline AFP + CA199 + Hsp90a & $0.991(0.980-1.000)$ & 91.5 & 100 & 40.4 & 57.5 \\
\hline CEA + CA199 + Hsp90a & $0.938(0.888-0.989)$ & 91.5 & 85.0 & 25.5 & 55.0 \\
\hline Four indexes combined & $0.993(0.982-1.000)$ & 97.9 & 92.5 & 21.3 & 50.0 \\
\hline
\end{tabular}



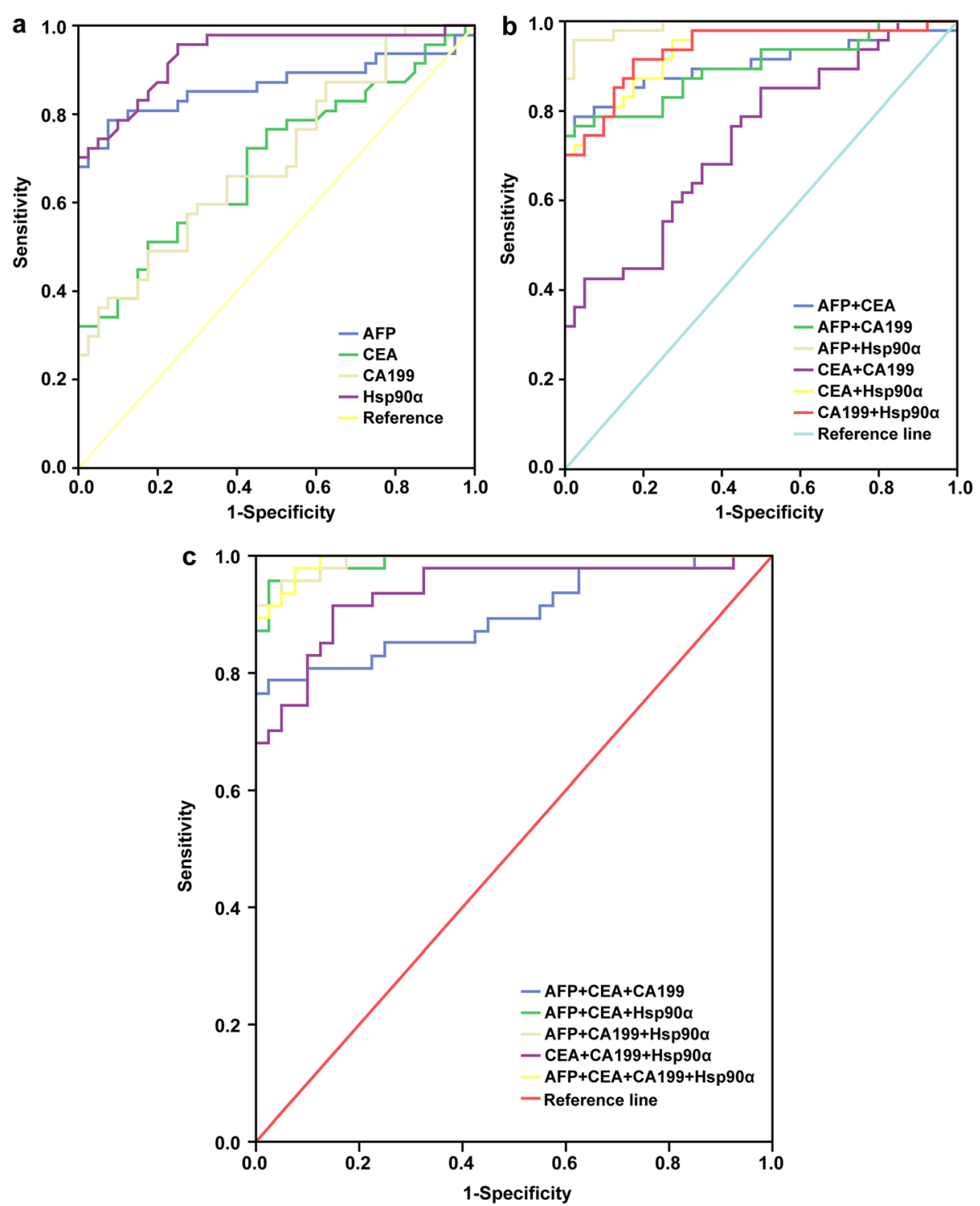

Fig. 2 ROC curve of four tumor markers for HCC. a shows the ROC curve of Hsp90a, AFP, CEA, and CA-199 alone in HCC patients. b shows the ROC curve of the combined application of any two of the four biomarkers Hsp90a, AFP, CEA, and CA-199 in HCC patients. c shows the ROC curve of the combination of any three of the four biomarkers Hsp90a, AFP, CEA, and CA-199 in HCC patients. ROC, receiver operating characteristic; HCC, hepatocellular carcinoma; SEN, sensitivity; SPE, specificity; Hsp90a, plasma heat shock protein 90 alpha; AFP, alpha-fetoprotein; CEA, carcinoembryonic antigen; CA199, carbohydrate antigen199

cancers than in those with stage III and stage IV liver cancers, and significantly higher than in patients with benign liver disease. It meant (1) Hsp90 $\alpha$ could reflect the malignant degree and disease progression of liver cancer and provided evidence for treatment plans. For

Table 7 Plasma levels of Hsp90a pre- and post-hepatic carcinectomy

\begin{tabular}{llll}
\hline & Number & Plasma Hsp90a level $(\mathbf{n g} / \mathbf{m L})$ & $\boldsymbol{P}$ value \\
\hline Preoperative & 44 & $249.29 \pm 142.82$ & $<0.001$ \\
Postoperative & & $131.01 \pm 63.23$ & \\
\hline
\end{tabular}

example, most stages I-II liver cancers could be treated locally to achieve the goal of radical cure, indicating that Hsp90 $\alpha$ had the potential to indicate whether it was feasible to receive the treatment of operation or ablation. (2) Hsp90 $\alpha$ has the potential to detect early-stage or small liver cancer, which could not be detected by current imaging approaches. Hence, it could play a certain role in the screening and follow-up of the high-risk population to improve the early diagnostic rate and resectability rate of liver cancer, or assist an imaging examination to detect small residual, recurrent, or metastatic lesions. It could also improve the prognosis and 
prolong the survival period of patients. Relevant basic research showed that Hsp90 $\alpha$ was secreted out of cells and promoted the invasion and metastasis of tumor cells by combining with the important invasion-related factor matrix metalloproteinase-2 $[7,19]$. In the early stage of tumor evolution, the preparation work of distant metastasis had begun [20].

The clinical characteristics of patients with liver cancer, including history of basic liver disease, active stage of basic liver disease, and different liver function grades, significantly affect the plasma level of Hsp90 $\alpha$. This indicates that the clinical application of Hsp90 $\alpha$ in the auxiliary diagnosis or differential diagnosis of liver cancer requires to pay close attention to the clinical condition and other related laboratory tests, so as to avoid falsepositive results and overdiagnosis and treatment as much as possible. Especially in the early diagnosis, the examination of the related symptoms and signs, drinking history, related basic liver disease and treatment history, HBV DNA test results, biochemical indicators of liver function (especially ALT/AST ratio), and so on are very important to the correct interpretation of Hsp90 $\alpha$. Correspondingly, data from a published clinical trial ever indicated the outstanding performance of Hsp90 $\alpha$ in diagnosing early cancer [21]. Meanwhile, it was speculated that the level of plasma Hsp90 $\alpha$ in patients with liver cancer who were diagnosed and treated could be used as a potential indicator of long-term prognosis. The synthesis and secretion of Hsp90 $\alpha$ by malignant tumor cells are independent to some extent, but the state of liver function is also an important factor. Therefore, poor antiviral effect, decompensation of liver function, large primary liver cancer, and late clinical stage are not only the factors for Hsp90 $\alpha$ overexpression but also the adverse factors for liver cancer prognosis [2, 22-26].

Furthermore, we found that plasma Hsp90 $\alpha$ fluctuance could reflect patient's response to hepatic carcinectomy, as there was a significant difference between preoperative and postoperative Hsp90 $\alpha$ levels. Plasma levels of Hsp90 $\alpha$ appeared to be associated with decreased tumor burden by surgery, and that was consistent with the existing reports [7]. It hints us that Hsp90 $\alpha$ is a good monitor for patients undergoing hepatic carcinectomy.

There is no doubt that some limitations in the present study should be realized. First, our study was a singlecenter trial, and our patients were retrospectively enrolled. Our results should be further evaluated in largesample prospective studies. Second, patients enrolled may not be able to represent the general population with liver cancer due to the relatively small sample size. We could not exclude the possibility of disease spectrum bias. Last but not least, we did not touch upon liver cancers related to nonalcoholic fatty liver disease (NAFLD) and alcohol-associated liver disease (AALD).

\section{Conclusion}

To sum up, plasma Hsp90 $\alpha$ could serve as a useful diagnostic biomarker in liver cancer as well as a predictor for surgery response. As it associates with several clinicopathological characteristics, further basic and clinical researches should be carried to elucidate the mechanisms regarding its fluctuance in patients and to explore novel therapeutic approaches.

\section{Acknowledgement \\ We would like to acknowledge the reviewers for their helpful comments on this paper.}

\section{Authors' contributions}

$H F, Y Z, D S$, and $L R$ finished data analysis. YH, YZ, LC, and ZL finished manuscript editing. The authors read and approved the final manuscript.

\section{Funding}

None

\section{Availability of data and materials}

Not applicable

\section{Declarations}

\section{Ethics approval and consent to participate}

Our study involved humans, who had signed informed consent. This study was designed in accordance with the Declaration of Helsinki and approved by the ethics committee of Tianjin Medical University Cancer Institute and Hospital, National Clinical Research Center for Cancer, Tianjin's Clinical Research Center for Cancer, Key Laboratory of Cancer Prevention and Therapy.

\section{Consent for publication}

Not applicable

\section{Competing interests}

The authors declare that they have no conflicts of interest.

\section{Author details}

'Department of Clinical Laboratory, Tianjin Medical University Cancer Institute and Hospital, National Clinical Research Center for Cancer, Tianjin's Clinical Research Center for Cancer, Key Laboratory of Cancer Prevention and Therapy, Tianjin 300060, China. ${ }^{2}$ Shanghai Institute of Immunology, Department of Immunology and Microbiology, Shanghai Jiao Tong University School of Medicine, Shanghai 200025, China. ${ }^{3}$ Xiangshengtong (Tianjin) Medical Laboratory, Tianjin 300384, China.

Received: 10 January 2021 Accepted: 18 May 2021

Published online: 04 August 2021

\section{References}

1. Sun $\mathrm{K}$, Zheng $\mathrm{R}$, Zeng $\mathrm{H}$, et al. Report of cancer incidence and mortality in different areas of China. 2015. China Cancer. 2019;28(1):1-11.

2. National Health and Family Planning Commission of PRC. Standardization of diagnosis and treatment for hepatocellular carcinoma (2017 edition). Chin J Digest Surg. 2017;16(7):635-47.

3. Cillo U, Vitale A, Grigoletto F, Farinati F, Brolese A, Zanus G, et al. Prospective validation of the Barcelona Clinic Liver Cancer staging system. J Hepatol. 2006;44(4):723-31 https://doi.org/10.1016/j.jhep.2005.12.015.

4. Gupta S, Bent S, Kohlwes J. Test characteristics of alpha-fetoprotein for detecting hepatocellular carcinoma in patients with hepatitis C. A systematic review and critical analysis. Ann Intern Med. 2003;139(1):46-50 https://doi.org/10.7326/0003-4819-139-1-200307010-00012.

5. Singal AG, Conjeevaram HS, Volk ML, Fu S, Fontana RJ, Askari F, et al. Effectiveness of hepatocellular carcinoma surveillance in patients with cirrhosis. Cancer Epidemiol Biomark Prev. 2012;21:793-9. 
6. Patel T. Increasing incidence and mortality of primary intrahepatic cholangiocarcinoma in the United States. Hepatology. 2001;33(6):1353-7 https://doi.org/10.1053/jhep.2001.25087.

7. Eustace BK, Sakurai T, Stewart JK, Yimlamai D, Unger C, Zehetmeier C, et al. Functional proteomic screens reveal an essential extracellular role for Hsp90 alpha in cancer cell invasiveness. Nat Cell Biol. 2004;6(6):507-14 https://doi. org/10.1038/ncb1131.

8. Wang $X$, Song $X$, Zhuo W, Fu Y, Shi H, Liang $Y$, et al. The regulatory mechanism of Hsp90alpha secretion and its function in tumor malignancy. Proc Natl Acad Sci U S A. 2009;106(50):21288-93 https://doi.org/10.1073/pna S.0908151106.

9. Fu Y, Xu X, Huang D, Cui D, Liu L, Liu J, et al. Plasma heat shock protein 90alpha as a biomarker for the diagnosis of liver cancer: an official, largescale, and multicenter clinical trial. EBioMedicine. 2017;24:56-63 https://doi. org/10.1016/j.ebiom.2017.09.007.

10. Liu W, Li J, Zhang P, Hou Q, Feng S, Liu L, et al. A novel pan-cancer biomarker plasma heat shock protein 90alpha and its diagnosis determinants in clinic. Cancer Sci. 2019;110(9):2941-59 https://doi.org/1 $0.1111 /$ cas. 14143.

11. Amin B, Edge SB, Greene $L$, et al. AJCC cancer staging manual. 8th ed. New York: Springer; 2017. https://doi.org/10.1007/978-3-319-40618-3

12. Eisenhauer EA, Therasse P, Bogaerts J, Schwartz LH, Sargent D, Ford R, et al. New response evaluation criteria in solid tumours: revised RECIST guideline (version 1.1). Eur J Cancer. 2009;45(2):228-47 https://doi.org/10.1016/j.ejca.2 008.10 .026$.

13. Chen JS, Hsu YM, Chen CC, Chen LL, Lee CC, Huang TS. Secreted heat shock protein 90alpha induces colorectal cancer cell invasion through CD91/LRP-1 and NF-kappaB-mediated integrin alphaV expression. J Biol Chem. 2010;285(33):25458-66 https://doi.org/10.1074/jbc.M110.139345.

14. Ding J, He X, Cheng X, Cao G, Chen B, Chen S, et al. A 4-gene-based hypoxia signature is associated with tumor immune microenvironment and predicts the prognosis of pancreatic cancer patients. World J Surg Oncol. 2021;19(1):123 https://doi.org/10.1186/s12957-021-02204-7.

15. Shi Y, Liu X, Lou J, Han X, Zhang L, Wang Q, et al. Plasma levels of heat shock protein 90 alpha associated with lung cancer development and treatment responses. Clin Cancer Res. 2014;20(23):6016-22 https://doi.org/1 0.1158/1078-0432.CCR-14-0174.

16. Tian WL, He F, Fu X, Lin JT, Tang P, Huang YM, et al. High expression of heat shock protein 90 alpha and its significance in human acute leukemia cells. Gene. 2014;542(2):122-8 https://doi.org/10.1016/j.gene.2014.03.046.

17. Yang $\mathrm{H}, \mathrm{HuO} \mathrm{J}$, Li X. Identification and validation of a five-gene prognostic signature for hepatocellular carcinoma. World J Surg Oncol. 2021;19(1):90 https://doi.org/10.1186/s12957-021-02202-9.

18. Zhou Y, Deng X, Zang N, Li H, Li G, Li C, et al. Transcriptomic and proteomic investigation of Hsp90A as a potential biomarker for HCC. Med Sci Monit. 2015;21:4039-49.

19. Eustace BK, Jay DG. Extracellular roles for the molecular chaperone, Hsp90. Cell Cycle. 2004;3(9):1098-100.

20. Harper KL, Sosa MS, Entenberg D, Hosseini H, Cheung JF, Nobre R, et al. Mechanism of early dissemination and metastasis in Her2(+) mammary cancer. Nature. 2016;540(7634):588-92 https://doi.org/10.1038/nature20609.

21. Kasanga M, Liu L, Xue L, Song X. Plasma heat shock protein 90 -alpha have an advantage in diagnosis of colorectal cancer at early stage. Biomark Med. 2018;12(8):881-90 https://doi.org/10.2217/bmm-2018-0155.

22. Budhu A, Forgues $\mathrm{M}$, Ye QH, Jia HL, He P, Zanetti KA, et al. Prediction of venous metastases, recurrence, and prognosis in hepatocellular carcinoma based on a unique immune response signature of the liver microenvironment. Cancer Cell. 2006;10(2):99-111 https://doi.org/10.1016/j. ccr.2006.06.016.

23. Hao K, Luk J, Lee $P$, et al. Predicting prognostics in hepatocellular carcinoma after curative surgery with common clinicopathologic parameters. BMC Cancer. 2009;9(1):389 https://doi.org/10.1186/1471-2407-9-389.

24. Kim JH, Choi MS, Lee H, Kim DY, Lee JH, Koh KC, et al. Clinical features and prognosis of hepatocellular carcinoma in young patients from a hepatitis Bendemic area. J Gastroenterol Hepatol. 2006;21(3):588-94 https://doi.org/1 0.1111/j.1440-1746.2005.04127.x.

25. Poon RT, Fan ST, Lo CM, Liu CL, Wong J. Intrahepatic recurrence after curative resection of hepatocellular carcinoma: long-term results of treatment and prognostic factors. Ann Surg. 1999;229(2):216-22 https://doi. org/10.1097/00000658-199902000-00009.
26. Yin J, Lin N, Han Y, et al. Effect of antiviral treatment with nucleotide/ nucleoside analogs on postoperative prognosis of hepatitis B virus-related hepatocellular carcinoma: a two-stage longitudinal clinical study. J Clin Oncol. 2013:31:3647-55.

\section{Publisher's Note}

Springer Nature remains neutral with regard to jurisdictional claims in published maps and institutional affiliations.
Ready to submit your research? Choose BMC and benefit from:

- fast, convenient online submission

- thorough peer review by experienced researchers in your field

- rapid publication on acceptance

- support for research data, including large and complex data types

- gold Open Access which fosters wider collaboration and increased citations

- maximum visibility for your research: over $100 \mathrm{M}$ website views per year

At BMC, research is always in progress.

Learn more biomedcentral.com/submissions 